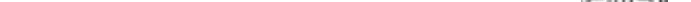




\title{
Jarudori - A terra ancestral dos Bororo
}

\author{
Antonio Hilário Aguilera URQUIZA
}

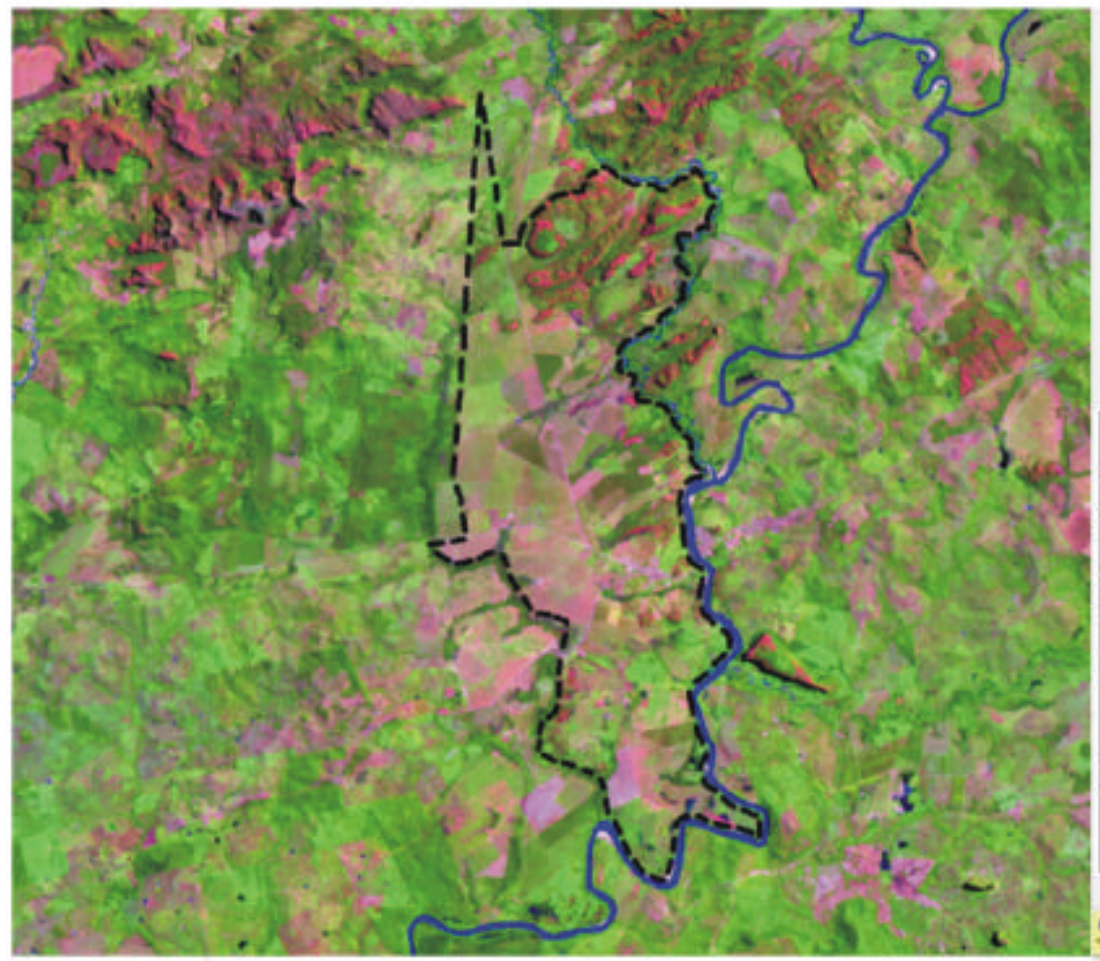

Nós, Boe Bororo, por motivo histórico, religioso e cultural não estamos dispostos a abrir mão de nossos direitos sobre estas terras, sobre este território Boe Bororo chamado Jarudóri (Gilberto Okoreo apud Barros \& Bordignon, 2003)

Nesta sessão de iconografia apresentamos visualmente a realidade da Terra Indígena Jarudori, demarcada pelo Marechal Rondon nos inícios do século XX e, na atualidade, totalmente ocupada por fazendeiros e por uma pequena cidade -

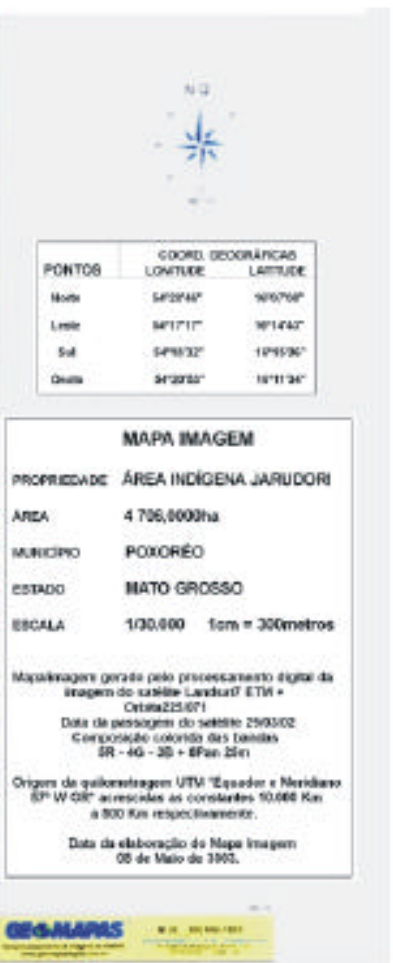

Doutor em Antropologia pela Universidade de Salamanca (Espanha); professor pesquisador da UFMS; membro do grupo de pesquisa sobre Educação Indígena e GEFIL - Grupo de Estudos e Pesquisas Filosóficas. hilario_aguilera@yahoo.es 
Distrito de Jarudori - no município de Poxoréo, no sudeste do Estado de Mato Grosso.

No depoimento de Luis Carlos Okoreo (2001), professor Bororo e aluno do Projeto Tucum, podemos perceber o nível de consciência e do sentimento que perpassa o povo Bororo em relação à ocupação de suas terras imemoriais:

Esta área recebeu o nome de São João do Jarudóri [...] Mas na década de 40 e 50 foi sendo invadida e os Bororo, com a chegada dos brancos, foram contraindo doenças e morrendo em grades quantidades. Sofreram também a exploração de mão-de-obra e a dispersão de várias famílias.

Com relação aos documentos históricos sobre o processo de demarcação da Área Indígena Jarudori, acontece um fato insólito, ou seja, a ausência do documento principal. Todas as referências bibliográficas sobre os Bororo, em perspectiva histórica, registram a demarcação dessas terras por Rondon, no início do século XX, embora não se tenha conseguido, ainda, localizar os documentos relativos a ela. Esse fato teria ocorrido por um motivo semelhante ao da TI Bororo de Teresa Cristina: de acordo com um documento oficial do Serviço de Proteção aos Índios e Localização de Trabalhadores Nacionais, de 1915, que trata das terras da Povoação de São Lourenço (Teresa Cristina), "cujos limites conheceis, ainda não foram transferidas ao domínio da União, oficialmente, sob o fundamento de terem desaparecido as cadernetas da medição feitas pelo Sr. Coronel Cândido Rondon, da qual, entretanto, existem memorial e planta" ${ }^{1}$. Inferimos, desse fato, que, com certeza, desapareceu também a caderneta da medição da área de "São João de Jarudóri", cujos limites são conhecidos até hoje por vários anciões Bororo, estando bastante presente na memória social desse povo (cf. Jardim, 1915, 379, f. 1065; apud Barros \& Bordignon, 2003).

Apresentamos a seguir o mapa do Município de Jarudori com seus respectivos distritos e, em destaque (vermelho) a Terra Indígena de Jarudori, como foi aprovada e homologada na década de 1950 pelo Governo Estadual e Federal, com 4.7 mil ha. 


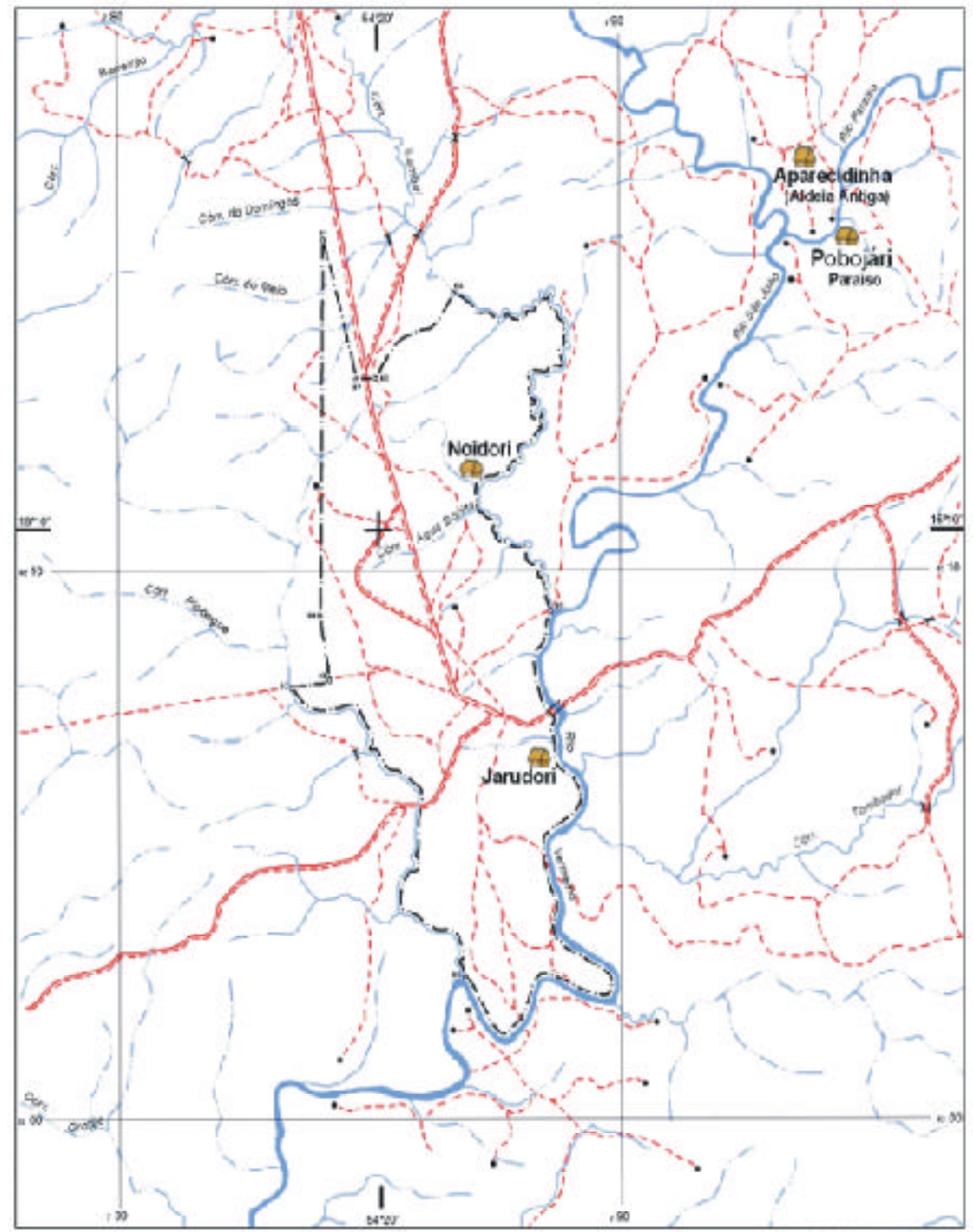

Wequade ne Hiows owe

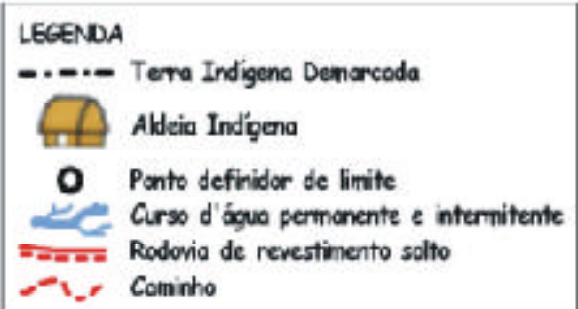

Mepo-base: Mepa da Áres Indigena Jarudore DPLARNAI. 1984.

Exala $1: 160200$

Fonte: Barros e Bordignon, 2003. 
Dentro desses limites existiram três aldeias, mais recentes: Nabureri, Pobojári (Paraíso) e Jarudóri, esta última, a mais importante, por se localizar em um território não só tradicional, mais sagrado e tematizado em mitos de origem, nos quais são invocados importantes demiurgos que organizaram social e simbolicamente a cosmologia dos Bororo.

No entanto, originalmente, esse território indígena, quando demarcado por Rondon, possuía a dimensão de 100 mil ha. E abrangia as principais aldeias e grande parte da população Bororo da época.

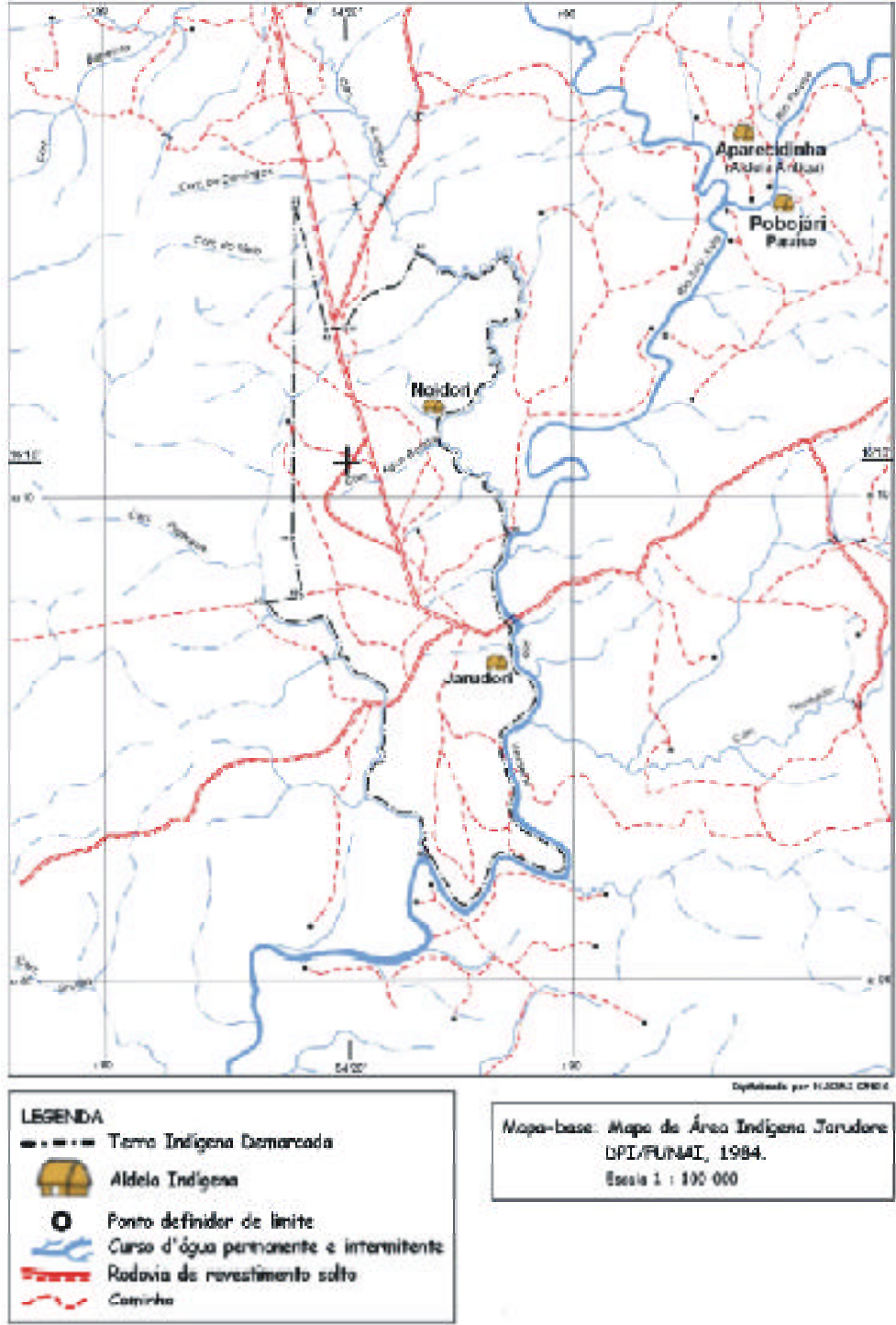

Fonte do mapa-base: Enciclopédia Bororo, v. 1 (Albisetti; Venturelli, 1962, p.282)

152 Antonio Hilário Aguilera URQUIZA. Jarudori - A terra ancestral dos Bororo 
Apenas para ilustrar, reproduzimos a seguir, um mapa que representa o "habitat dos Bororo", envolvendo a região de Jarudori, seguido da relação das aldeias que existiam e as que ainda continuam a existir nesta região.

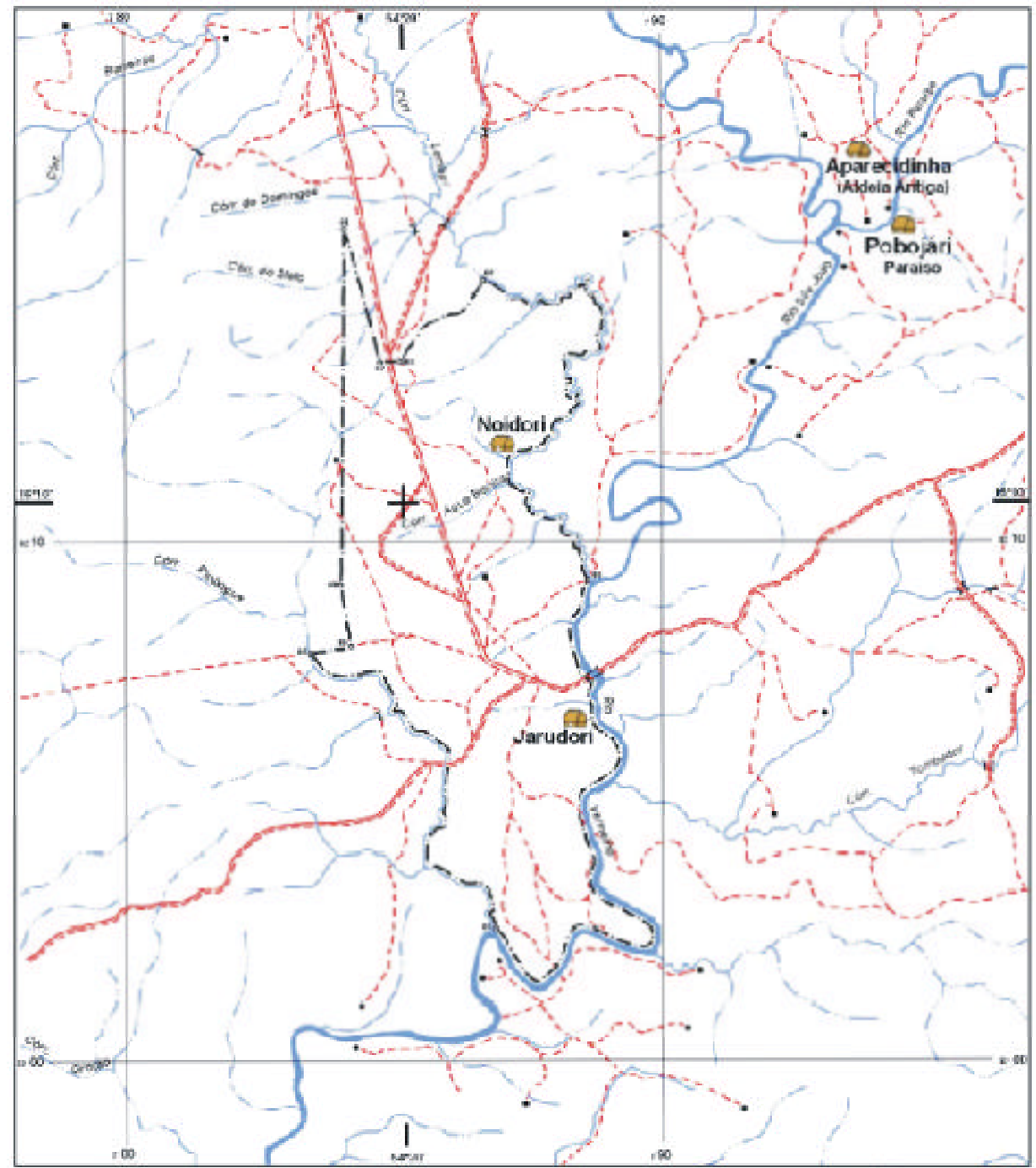

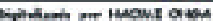

\begin{tabular}{|c|c|}
\hline \\
\hline \multicolumn{2}{|c|}{$\begin{array}{l}\text { LBGENDA } \\
---- \text { - Terra Indigeno Demarcada }\end{array}$} \\
\hline & Aldeia Indigena \\
\hline & $\begin{array}{l}\text { Ponto definider de limite } \\
\text { Curso d'ógua pemnorknte e intermitente }\end{array}$ \\
\hline$\Rightarrow=$ & Radovia de revestimento solto \\
\hline & Caninhe \\
\hline
\end{tabular}

Mapa-base: Mopa do Área Indigena Jarudore DPI/FUNAI, 1984

Escala $t=100000$ 


\section{TERRA INDÍGENA DE JARUDORI}

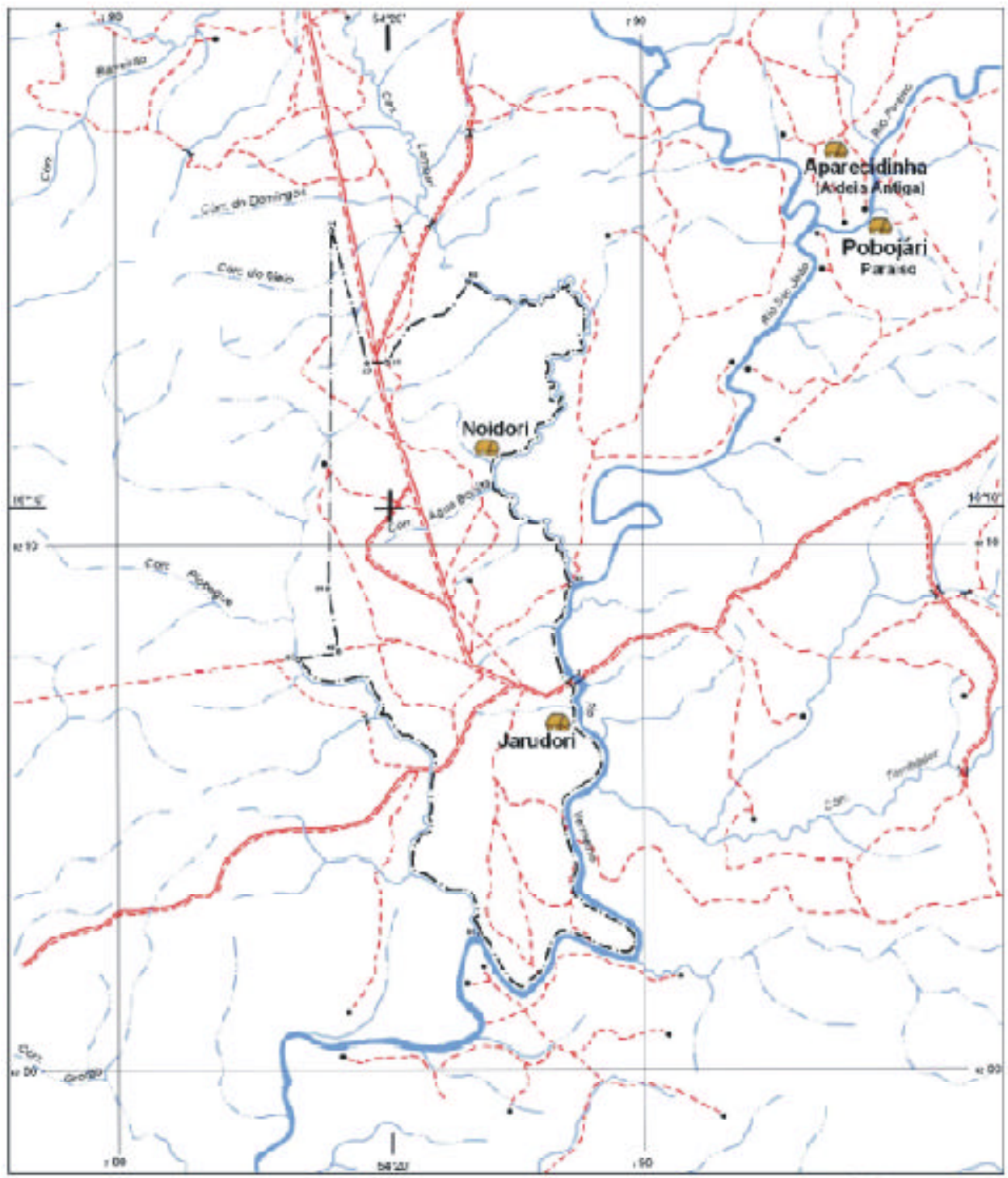

Deptotesede par hecriver cones

LEGENDA

-..- Terra Indígena Demareada

Aldesa Indigena

- Ponto definidor de limite

Curso d'águo permenente e internitente Rodovia de revestimento solto

=.t.-. Rodovia
Mapa-bose: Mapa de Áreo Indigena Jarudore DPI/AUNAI, 1984.

Exala $1 ; 100000$

154 Antonio Hilário Aguilera URQUIZA. Jarudori - A terra ancestral dos Bororo 


\section{Nota}

${ }^{1}$ Jardim, 1915, 379, f. 1065.

\section{Referências}

ALBISETTI, C. E.; VENTURELLI, A. J. Enciclopédia Bororo I. Campo Grande, 1962. BARROS, Edir Pina de; BORDIGNON, Mário. Jarudori - Estudos e Levantamentos Prévios Histórico-Antropológicos. Relatório relativo ao Termo de Referência DAF/ DEID n. 53/2002, do Departamento de Identificação e Delimitação da Diretoria de Assuntos Fundiários/FUNAI. Brasília (DF), 2003.

COLBACCHINI, Antonio; ALBISETTI, C. Os Bororos orientais. Cia. Ed. Nacional, Série Brasiliana, Grande Formato, 1942 (I Bororos Orientali Orarimugudoge del Matto Grosso, Brasile, Itália, 1925).

OKOREO, Luiz Carlos. Terra de Jarudori. Trabalho final do Projeto Tucum, Pólo IIIBoe Bororo. Rondonópolis, Secretaria de Educação do Estado de Mato Grosso/ Município de Rondonópolis, fevereiro de 2001.

Recebido em 02 de janeiro de 2007. Aprovado para publicação em 05 de fevereiro de 2007. 